\title{
ARBITRAGE IN POLITICAL PREDICTION MARKETS
}

\author{
Andrew Stershic* \\ Department of Civil and \\ Environmental Engineering \\ Duke University \\ Durham, NC 27708, USA
}

\author{
Kritee Gujral \\ The CHOICE Institute, \\ University of Washington, \\ Seattle, WA 98195, USA
}

\begin{abstract}
Online prediction markets are a powerful tool for aggregating information and show promise as predictive tools for uncertain outcomes, from sporting events to election results. However, these markets only serve as effective prediction tools so long as the market pricing remains efficient. We analyze the potential arbitrage profits derived from such mispricings in two leading American political prediction markets, PredictIt (for the 2016 and 2020 elections) and the Iowa Electronic Markets (for the 2016 election), to quantify the degree of mispricing and to show how market design can contribute to price distortion. We show that contracts hosted by PredictIt, compared to the IEM, are chronically mispriced, with large arbitrage profits in the 2016 election markets and tangible profits for the 2020 markets. We discuss the role of profit fees and contract limits, the primary differences between the PredictIt and IEM, in distorting pricing on Predictlt by limiting the ability of traders to capture arbitrage profits. Additionally, we examine the association between arbitrage and margin-linking, increased liquidity, and the number of unique contracts in PredictIt's markets. This research provides cautionary evidence of potential inefficiencies in prediction markets with the intention of improving market implementation and enhancing market predictiveness.
\end{abstract}

\section{INTRODUCTION}

Political uncertainty can have an enormous impact on business and investment decisions globally (Julio and Yook, 2016; Kelly et al., 2016). Election uncertainty, in particular, is something researchers have tried to overcome for decades through developing a series of methods for forecasting election outcomes. While one method of eliminating such uncertainty is to aggregate the opinions of the electorate via election polls, an alternative and relatively new method is to utilize the price system of the market, i.e., asking people to

\footnotetext{
* Present Affiliation: Sandia National Laboratories, 7011 East Avenue, Livermore, CA 94550, USA
} 
"put their money where their mouth is" through participation in political prediction markets (Servan-Schreiber et al., 2004; Graefe, 2017).

Prediction markets are exchanges in which participants buy and sell contracts that typically correspond to binary states at a certain time in the future. Accordingly, these contracts resolve to a specified payout value if the contract state is true at the settlement date or expire worthless if it is false. The prediction market serves to predict the event's outcome, much in the way that a futures contract reflects the expectation of the underlying asset's value at a future time (Ederington, 1979). These markets operate similarly to stock exchanges and other financial markets wherein traders have a profit incentive to seek the truth about the contract's underlying event. For example, if a trader has found evidence that Event A will occur, he or she may buy shares of the Event A contract in a prediction market. With enough trading volume, the price moves upward. Accordingly, one can interpret the price of the contract as the market's aggregate estimate of the probability of that event's occurrence.

The concept of market pricing representing the aggregation of information was discussed by Hayek (1945). He noted that a market with many participants contributing partial information performs the same function that an omniscient price-setter would. In this way, the market functions not only as a setting for commodity exchange, but as an effective means to aggregate information. Participants may trade the contract either as speculators, who expect to profit from the realization of their prediction; or hedgers, who trade to mitigate risk outside the market; or as arbitrageurs, who seek to profit from market mispricings.

Interest in prediction markets has grown exponentially since the 1990s as these markets offer promising mechanisms for aggregating information dispersed among several market agents (Tziralis and Tatsiopoulos, 2012). Manski (2006) concluded that market prices in prediction markets reflect the aggregation of market participants' beliefs, risk tolerance, and available funds. Ray (2006) listed the conditions required for prediction markets to be predictive, to represent the "wisdom of crowds": a diversity of opinions, the ability to bet independently of others, and the ability to act on specialized information without influencing the event in question. Most importantly, prediction markets have been shown to predict actual election outcomes with a remarkable degree of accuracy, outperforming polls (Forsythe et al., 1992; Wolfers and Zitzewitz, 2004, 2006; Berg et al., 2008a,b; Majumder et al., 2009; Graefe, 2017).

Nonetheless, most recently, prediction markets have garnered renewed attention due to their "failures" in predicting the results of the Brexit referendum and the 2016 U.S. presidential election. As there is evidence of rational players in other markets anticipating these results better than prediction markets could (Blau et al. 2019), it is necessary to ensure that prediction markets are indeed as sound as we believe them to be. Examining successes and pitfalls of prediction markets has become increasingly important, especially given the growing use of social media, the strong positive association between social media use and political misinformation (Valenzuela et al., 2019), and emerging social media platforms 
that either host prediction markets or mimic their aggregation mechanism. (Ritterman et al., 2009; Schoen et al., 2013; Lewandowsky et al., 2017). It is necessary to fine-tune our understanding of prediction market mechanisms in order to avoid prediction failures in existing markets and to inform the market design and implementation of emerging market platforms.

Although prediction markets appear to offer a promising mechanism for aggregating information and beliefs, and could prove even more fruitful in the recent age of misinformation than was imagined at their outset, there is a notable gap in studies examining efficiency in these markets outside the context of financial prediction markets (Kildal et al., 2012; Croxson and Reade, 2013). Efficiency studies are especially rare for election forecasting markets even though these markets are considered some of the more successful types of prediction markets (Kildal et al., 2012, Graefe, 2017). Regulatory constraints imposed on prediction markets in the United States lead to fewer such markets in operation than may be optimal or desired (Arrow et al, 2008). Among other factors, a lack of sufficient competition among prediction markets can naturally result in inefficiencies, which could greatly diminish the accuracy, the predictive power, and thereby the promise they offer. Thus, it is crucial to assess the efficiency of political prediction markets, especially given their growing popularity and the information landscape changing so significantly and rapidly.

Table 1 provides a limited summary of the literature on sports betting and election market efficiency. Most of the prediction market efficiency literature has focused on sport betting markets rather than on election markets. As efficiency across market domains can differ (Tetlock, 2004), additional research on election market efficiency would be advantageous. Among efficiency studies of election markets, much of the evidential support comes from the Iowa Electronic Markets (IEM), which have been shown to be fairly efficient despite irrational traders and/or behavior (Forsythe et al., 1999; Oliven and Rietz, 2004), yet other election markets have undergone much less scrutiny. ${ }^{1}$ This limited set of literature has not amassed enough studies nor sufficient consensus on all aspects of efficiency. Rather, prediction market studies have focused on different types of market efficiency. Several studies have examined the impact of information releases on price efficiency, and have found mixed evidence regarding the effect of new information on price efficiency, as well as regarding response time for prices to adjust to new information.

An important form of (and the weakest condition for) market efficiency (Rhode and Strumpf, 2004; Rothschild and Pennock, 2014), arbitrage, has been underexplored (Luckner and Weinhardt, 2008; Kildalet al., 2012). In markets where arbitrage opportunities cannot be exploited, the interpretation of prices as probability measures can become problematic (Wolfers and Zitzewitz, 2004;

\footnotetext{
1 Even outside the context of efficiency studies, IEM studies make up 43\% of the applied election market literature, and all other international and domestic political markets combined make up the remaining 57\% (Tziralis and Tatsiopoulos, 2012).
} 
Table 1. Limited summary of the literature analyzing efficiency of sports betting markets and election forecasting markets.

\begin{tabular}{|c|c|c|c|c|}
\hline Study & Year & Type of Efficiency & Key Finding & $\begin{array}{l}\text { Market (Years) } \\
\text { Studied }\end{array}$ \\
\hline $\begin{array}{l}\text { Forsythe } \\
\text { et al. (1999) }\end{array}$ & 1999 & $\begin{array}{l}\text { Systematic biases } \\
\text { and mistakes of } \\
\text { traders (including } \\
\text { arbitrage violations) }\end{array}$ & $\begin{array}{l}\text { Arbitrage opportunities and } \\
\text { wish fulfillment biases are } \\
\text { reproduced in laboratory } \\
\text { experiments, consistent with } \\
\text { those observed in election } \\
\text { markets. However, unlike } \\
\text { arbitrage in field } \\
\text { experiments, arbitrage in lab } \\
\text { experiments is larger, more } \\
\text { persistent, and causes prices } \\
\text { to be greatly inaccurate. } \\
\text { Overall, such arbitrage has } \\
\text { little or no effect on market } \\
\text { efficiency. }\end{array}$ & $\begin{array}{l}\text { Review of prior } \\
\text { literature and } \\
\text { lab experiment } \\
\text { (labeled } \\
\text { OPIW-1) }\end{array}$ \\
\hline $\begin{array}{l}\text { Rhode and } \\
\text { Strumpf } \\
\text { (2004) }\end{array}$ & 2004 & $\begin{array}{l}\text { Arbitrage-free } \\
\text { pricing; weak-, } \\
\text { semistrong-, and } \\
\text { strong-form } \\
\text { efficiency }\end{array}$ & $\begin{array}{l}\text { The market was fairly } \\
\text { efficient on all of these } \\
\text { fronts. Arbitrage was rare } \\
\text { and short-lived. }\end{array}$ & $\begin{array}{l}\text { Election betting } \\
\text { in New York } \\
\text { (1884-1928) }\end{array}$ \\
\hline $\begin{array}{l}\text { Oliven and } \\
\text { Rietz (2004) }\end{array}$ & 2004 & $\begin{array}{l}\text { Individual rationality } \\
\text { and arbitrage by two } \\
\text { types of traders: } \\
\text { "market makers" and } \\
\text { "price takers" }\end{array}$ & $\begin{array}{l}\text { Markets appear efficient, } \\
\text { despite a high frequency of } \\
\text { apparently irrational } \\
\text { trader behavior (including } \\
\text { arbitrage), owing to the } \\
\text { relatively less mistake- } \\
\text { prone "market making" } \\
\text { traders. }\end{array}$ & IEM (1992) \\
\hline $\begin{array}{l}\text { Luckner and } \\
\text { Weinhardt } \\
(2008) \\
\end{array}$ & 2008 & $\begin{array}{l}\text { Intra-market } \\
\text { arbitrage }\end{array}$ & $\begin{array}{l}\text { There are few substantial } \\
\text { opportunities available. }\end{array}$ & $\begin{array}{l}\text { STOCCER } \\
(2006)\end{array}$ \\
\hline $\begin{array}{l}\text { Vlastakis } \\
\text { et al. (2009) }\end{array}$ & 2009 & $\begin{array}{l}\text { Inter-market } \\
\text { arbitrage and betting } \\
\text { biases }\end{array}$ & $\begin{array}{l}\text { There exist limited but } \\
\text { highly profitable arbitrage } \\
\text { opportunities, as well as the } \\
\text { favorite-longshot bias (FLB) } \\
\text { and an "away-favorite" bias. }\end{array}$ & $\begin{array}{l}\text { Bet365, } \\
\text { Internet1×2, } \\
\text { Interwetten, } \\
\text { Sportingbet, } \\
\text { and William Hill } \\
(2002-2004)\end{array}$ \\
\hline $\begin{array}{l}\text { Kildal et al. } \\
(2012)\end{array}$ & 2012 & $\begin{array}{l}\text { Arbitrage across } \\
\text { borders and markets }\end{array}$ & $\begin{array}{l}\text { Arbitrage opportunities are } \\
\text { rare and difficult to exploit, } \\
\text { but some such opportunities } \\
\text { do exist across markets. }\end{array}$ & $\begin{array}{l}\text { Intrade } \\
(2006-2008) \\
\text { and iPredict } \\
(2008)\end{array}$ \\
\hline Page (2012) & 2012 & $\begin{array}{l}\text { Favorite-longshot } \\
\text { bias (FLB) }\end{array}$ & Market exhibits FLB. & $\begin{array}{l}\text { Tradesports. } \\
\text { com } \\
(2006-2007)\end{array}$ \\
\hline $\begin{array}{l}\text { Croxson and } \\
\text { Reade } \\
(2013)\end{array}$ & 2013 & $\begin{array}{l}\text { Price efficiency } \\
\text { response time to } \\
\text { news information. }\end{array}$ & $\begin{array}{l}\text { Prices update swiftly and } \\
\text { fully. }\end{array}$ & $\begin{array}{l}\text { Betfair } \\
(2004-2013)\end{array}$ \\
\hline
\end{tabular}


Table 1. (continued)

\begin{tabular}{|c|c|c|c|c|}
\hline Study & Year & Type of Efficiency & Key Finding & $\begin{array}{l}\text { Market (Years) } \\
\text { Studied }\end{array}$ \\
\hline $\begin{array}{l}\text { Rothschild } \\
\text { and } \\
\text { Pennock } \\
\text { (2014) }\end{array}$ & 2014 & $\begin{array}{l}\text { Inter-market } \\
\text { arbitrage, intra- } \\
\text { market arbitrage, } \\
\text { and other forms of } \\
\text { bounded irrationality. }\end{array}$ & $\begin{array}{l}\text { Markets appear generally } \\
\text { efficient despite the } \\
\text { existence of the inefficiencies } \\
\text { studied. Changes in } \\
\text { prediction market design can } \\
\text { minimize these efficiencies. }\end{array}$ & $\begin{array}{l}\text { Intrade (2012) \& } \\
\text { Betfair (2012) }\end{array}$ \\
\hline $\begin{array}{l}\text { Vaughan } \\
\text { Williams and } \\
\text { Reade } \\
(2016)\end{array}$ & 2016 & $\begin{array}{l}\text { Price efficiency } \\
\text { response time to } \\
\text { tweets }\end{array}$ & $\begin{array}{l}\text { Mostly efficient. Slow response } \\
\text { of tweets, but quick response } \\
\text { to more credible news }\end{array}$ & Betfair (2010) \\
\hline $\begin{array}{l}\text { Brown et al. } \\
(2019)\end{array}$ & 2019 & $\begin{array}{l}\text { Price efficiency } \\
\text { post-poll information } \\
\text { release }\end{array}$ & $\begin{array}{l}\text { Price efficiency declines } \\
\text { temporarily post a poll- } \\
\text { release owing to attracting } \\
\text { relatively inexperienced } \\
\text { traders, and recovers when } \\
\text { more experienced traders } \\
\text { enter some hours later. Thus, } \\
\text { poll releases do not increase } \\
\text { price efficiency. }\end{array}$ & \begin{tabular}{|l} 
Intrade \\
$(2008-2012)$
\end{tabular} \\
\hline $\begin{array}{l}\text { Berg and } \\
\text { Rietz (2019) }\end{array}$ & 2019 & $\begin{array}{l}\text { Longshot bias and } \\
\text { the overconfidence } \\
\text { bias. }\end{array}$ & $\begin{array}{l}\text { Markets appear efficient at } \\
\text { short horizons, but non- } \\
\text { market data indicate some } \\
\text { intermediate-horizon } \\
\text { inefficiency. }\end{array}$ & $\begin{array}{l}\text { IEM } \\
(1995-2000)\end{array}$ \\
\hline $\begin{array}{l}\text { Auld and } \\
\text { Linton (2019) }\end{array}$ & 2019 & $\begin{array}{l}\text { Responses of a } \\
\text { political prediction } \\
\text { market and of a } \\
\text { currency market to } \\
\text { the EU referendum } \\
\text { results } \\
\text { announcement. }\end{array}$ & $\begin{array}{l}\text { Both markets appeared } \\
\text { inefficient, and the political } \\
\text { market seemed less } \\
\text { inefficient than the currency } \\
\text { market. }\end{array}$ & Betfair (2016) \\
\hline $\begin{array}{l}\text { Schmitz and } \\
\text { Rothschild } \\
\text { (2019) }\end{array}$ & 2019 & Trader efficiency & $\begin{array}{l}\text { Numerous traders made } \\
\text { inefficient trades. }\end{array}$ & Predictlt (2016) \\
\hline $\begin{array}{l}\text { Restocchi } \\
\text { et al. (2019) }\end{array}$ & 2019 & $\begin{array}{l}\text { Favorite-longshot } \\
\text { bias (FLB) }\end{array}$ & $\begin{array}{l}\text { Markets exhibit FLB, and the } \\
\text { level of FLB decreases with } \\
\text { duration of the market. }\end{array}$ & $\begin{array}{l}\text { Predictlt } \\
\text { (2014-2016) }\end{array}$ \\
\hline
\end{tabular}

Sethi, 2015a, 2016; Berg and Rietz, 2019). In particular, markets that impose transaction costs and/or profit fees can lead to mispricing (Berg and Rietz, 2019). Note that the generally popularized notion that prediction markets are efficient stems primarily from the efficiency of the IEM. However, the IEM has key features, such as account limits for avoiding any one trader to become too large, no trading fees, and a simple arbitrage structure, which allow the market to operate efficiently in spite of irrational trader behavior (Berg and Rietz, 2019). That there exist arbitrageurs in other prediction markets as well appears untested 
in the recent literature. Only a handful of prediction market studies have examined arbitrage, many of which have focused on inter-market arbitrage rather than intra-market arbitrage, and such arbitrage studies appear to have declined over time. This decline in studies of arbitrage is unsurprising given that apart from a few warning signals, early studies found few opportunities of arbitrage, which were typically short-lived, and markets appeared to perform efficiently despite arbitrage violations (Forsythe et al., 1999; Oliven and Rietz, 2004). However, as there is insufficient evidence of large and persistent arbitrage opportunities, it is unclear if prediction markets, generally (and not just the IEM), would also perform well under larger and more persistent arbitrage opportunities. Thus, it is important to take an updated look at election market efficiency, and arbitrage is an important and natural starting point for studying market efficiency (Vlastakis, 2009). Studying intra-market arbitrage can be particularly advantageous as it eliminates currency risk issues and fee- and contract-structure differences that can obfuscate analyses of inter-market arbitrage. Additionally, as a potential intra-market arbitrageur would only need to follow one market rather than two, opportunities should be easier to detect and utilize, making intramarket arbitrage less frequent in efficient markets (Kildal et al., 2009).

This paper focuses on identifying arbitrage opportunities in PredictIt, a market that is similar to the well-functioning IEM, yet has some key market design differences. PredictIt is a relatively new and understudied market that has nonetheless gained significant popularity in recent years. We hypothesize that due to key market design differences between IEM and PredictIt, especially with respect to fee structure and contract limits, PredictIt will exhibit signs of inefficiency, such as unexploited arbitrage opportunities, that are atypical of a well-functioning market such as the IEM. Additionally, we test the association between arbitrage and margin-linking introduced in 2015, increased liquidity, and the number of unique contracts.

Using recent PredictIt data from the 2016 and the upcoming 2020 U.S. presidential elections and IEM data from the U.S. 2016 election, this paper shows large and persistent mispricings in PredictIt. The findings from Predictlt are compared to those from IEM. Market design differences, such as profit fees and contract limits, that could contribute to the mispricings and arbitrage opportunities observed on PredictIt are then discussed. PredictIt and IEM have been compared briefly in blog posts (Sethi, 2015a,b, 2016), and PredictIt price inefficiency has been briefly mentioned by a recent working paper (Schmitz and Rothschild, 2019) which uses PredictIt data from one U.S. state to test trader efficiency. Nevertheless, there is no formal or in-depth study focusing on PredictIt's mispricings and arbitrage opportunities. This paper contributes to the emerging work analyzing this relatively understudied yet increasingly important market and to the sparse literature on political prediction market efficiency with the intention of improving the functioning of political prediction markets.

This paper is organized as follows: Sec. 2 describes and compares the market structure of PredictIt and IEM. Sec. 3 presents the conceptual 
framework used for identifying arbitrage opportunities in political prediction markets, with a focus on PredictIt. Sec. 4 presents the analysis and the key findings, with discussion of market design aspects and trader experience that play a role in market mispricings. Finally, a brief summary and concluding remarks are given in Sec. 5.

\section{PREDICTIT AND IEM}

The study focuses on the PredictIt market and compares it to the IEM, as these are both considered comparable markets, yet have some key market design differences that allow for understanding the impact of market design features on the functioning of these markets. While IEM hosts markets in both winner-take-all and vote-share formats, we focus on the winner-take-all markets as they provide the greatest parallel to PredictIt's offerings. A systematic comparison of PredictIt and IEM using the key market design criteria proposed in Spann and Skiera (2003) is presented in Table 2.

The PredictIt market (Victoria University of Wellington, 2015a) is operated by the Victoria University of Wellington, New Zealand. Since 2014, it has strongly focused its markets on national elections in the United States and has later expanded to predict many other consequential political events both in the U.S. and worldwide. As a research tool, PredictIt operates with a letter of no-action from the U.S. Commodity Futures Trading Commission (CFTC) that removes the risk of government prosecution (Victoria University of Wellington, 2015a; U.S. Commodity Futures Trading Commission, 2014). PredictIt is open for U.S.-dollar trading to U.S. residents from 48 states as well as non-U.S. residents (Victoria University of Wellington, 2015a). To maintain an academic setting, PredictIt limits each contract to only 5,000 unique traders at one time, with each trading position limited to $\$ 850$ in value (Victoria University of Wellington, 2015a; U.S. Commodity Futures Trading Commission, 2014). IEM similarly acts with CFTC permission and contract position limits.

Secondly, PredictIt and IEM are both academic markets. Due to the legal particularity that marks prediction markets in the U.S., academic markets have been historically more successful than non-academic markets (Arrow et al., 2008). Generally, the U.S. government considers buying and selling shares in an unregulated market using U.S. dollars to be unlawful gambling, or if the contracts represent financial events, an unregulated financial market (Brito et al., 2014). Consequently, the most successful markets have operated with governmental permission as part of academic studies, as these two markets have. Outside of the academic context, political prediction markets have been less successful. As there are few prediction markets due to the regulatory constraints, and as academic ones are most likely to succeed, PredictIt and IEM are important to study and compare.

As can be seen in Table 2, IEM and PredictIt are similar across key design features. Compared to PredictIt, IEM hosts markets of relatively shorter 
durations, and uses closed order book (vs. open order book), i.e., lists only the best bids/asks (vs. all bids/asks). We focus the discussion in this paper on two key differences between the IEM and PredictIt: profit fees and contract limit constraints on arbitrage trading. Additionally, we examine the relationship between margin-linking introduced in 2015, increased liquidity, and the number of unique contracts on the functioning of PredictIt, factors that are considered important for the performance of prediction markets.

Table 2. Comparison of IEM and PredictIt markets using the framework in Spann and Skiera (2003).

\begin{tabular}{|c|c|c|c|}
\hline $\begin{array}{l}\text { Steps for Market } \\
\text { Design }\end{array}$ & $\begin{array}{l}\text { Design } \\
\text { Considerations }\end{array}$ & IEM & Predictlt \\
\hline \multirow[t]{4}{*}{$\begin{array}{l}\text { Choice of } \\
\text { forecasting goal }\end{array}$} & $\begin{array}{l}\text { Selection of the } \\
\text { prediction issue }\end{array}$ & $\begin{array}{l}\text { Issues chosen by the } \\
\text { IEM Board of Directors }\end{array}$ & $\begin{array}{l}\text { Issues chosen by } \\
\text { Victoria University of } \\
\text { Wellington, New } \\
\text { Zealand. }\end{array}$ \\
\hline & $\begin{array}{l}\text { Formulation for the } \\
\text { payoff function }\end{array}$ & $\begin{array}{l}\text { Vote Share } \\
\text { (proportional payoff) \& } \\
\text { Winner Take All } \\
\text { (Boolean) }\end{array}$ & $\begin{array}{l}\text { Boolean: } \$ 1 / \text { share if } \\
\text { win; } \$ 0 \text { if loss }\end{array}$ \\
\hline & $\begin{array}{l}\text { Duration of the virtual } \\
\text { stock market }\end{array}$ & $\begin{array}{l}\text { Depends: most of a } \\
\text { year }(2016) \text {, Over one } \\
\text { year (2020: } 2 / 7 / 19- \\
11 / 3 / 20)\end{array}$ & $\begin{array}{l}\text { Depends: typically two } \\
\text { years + }(2016,2020 \\
\text { markets })\end{array}$ \\
\hline & $\begin{array}{l}\text { Open to the public or } \\
\text { limited participation } \\
\text { (specific groups or } \\
\text { time periods) }\end{array}$ & $\begin{array}{l}\text { Open to the public } \\
(24 / 7) ; \text { US \& non-US } \\
\text { traders }\end{array}$ & $\begin{array}{l}\text { Open to the public } \\
\text { (24/7); US \& non-US } \\
\text { traders; Maximum } \\
5000 \text { traders per } \\
\text { contract }\end{array}$ \\
\hline \multirow{6}{*}{$\begin{array}{l}\text { Incentives for } \\
\text { participation and } \\
\text { information } \\
\text { revelation }\end{array}$} & $\begin{array}{l}\text { Composition of initial } \\
\text { portfolios/endowment }\end{array}$ & None provided & None provided \\
\hline & $\begin{array}{l}\text { Investment of real } \\
\text { money or endowment }\end{array}$ & Real money & Real money \\
\hline & $\begin{array}{l}\text { Remuneration/ } \\
\text { incentive mechanism }\end{array}$ & $\begin{array}{l}\text { Traders remunerated } \\
\text { per share of correct } \\
\text { prediction }\end{array}$ & $\begin{array}{l}\text { Traders remunerated } \\
\text { per share of correct } \\
\text { prediction }\end{array}$ \\
\hline & $\begin{array}{l}\text { Monetary versus } \\
\text { nonmonetary rewards }\end{array}$ & Monetary & Monetary \\
\hline & $\begin{array}{l}\text { Linear relationship } \\
\text { between performance } \\
\text { and reward versus }\end{array}$ & Linear / Zero-Sum & Linear / Zero-Sum \\
\hline & $\begin{array}{l}\text { - If zero-sum game: } \\
\text { "unit portfolios" or } \\
\text { "jackpot" }\end{array}$ & Unit portfolios & Unit portfolios \\
\hline \multirow{2}{*}{$\begin{array}{l}\text { Financial market } \\
\text { design }\end{array}$} & Trading mechanism: & & \\
\hline & $\begin{array}{l}\text { - Market maker (i.e., } \\
\text { dealer) }\end{array}$ & No & No \\
\hline
\end{tabular}


Table 2. (continued)

\begin{tabular}{|l|l|l|l|}
\hline $\begin{array}{l}\text { Steps for Market } \\
\text { Design }\end{array}$ & $\begin{array}{l}\text { Design } \\
\text { Considerations }\end{array}$ & IEM & Predictlt \\
\hline \multirow{4}{*}{$\begin{array}{l}\text { - Double auction } \\
\text { (open or closed order } \\
\text { book) }\end{array}$} & $\begin{array}{l}\text { Double Auction / } \\
\text { Closed Order Book } \\
\text { (only best bid/ask } \\
\text { shown) }\end{array}$ & $\begin{array}{l}\text { Double Auction / Open } \\
\text { Order Book }\end{array}$ \\
\cline { 2 - 4 } & Trading hours & Internet-based / 24-7 & Internet-based / 24-7 \\
\cline { 2 - 4 } & $\begin{array}{l}\text { Long and/or short } \\
\text { trading }\end{array}$ & $\begin{array}{l}\text { Long; Short selling } \\
\text { equivalent via bundles }\end{array}$ & Long and Short \\
\cline { 2 - 4 } & $\begin{array}{l}\text { Order types: Limit } \\
\text { and/or market; } \\
\text { possible temporal } \\
\text { restrictions }\end{array}$ & $\begin{array}{l}\text { Limit and Market } \\
\text { (trader can buy/sell at } \\
\text { existing bid/ask price, } \\
\text { or place bid/ask that } \\
\text { fulfilled when } \\
\text { matched) }\end{array}$ & $\begin{array}{l}\text { Limit and Market } \\
\text { (trader can buy/sell at } \\
\text { existing bid/ask price, } \\
\text { or place bid/ask that } \\
\text { fulfilled when matched) }\end{array}$ \\
\cline { 2 - 4 } & $\begin{array}{l}\text { Position limits and } \\
\text { price limits }\end{array}$ & $\begin{array}{l}\text { \$500 across all } \\
\text { contracts in account. }\end{array}$ & $\begin{array}{l}\text { Each contract is limited } \\
\text { to only 5,000 unique } \\
\text { traders at one time, } \\
\text { with each trading } \\
\text { position limited to } \$ 850 \\
\text { in value. }\end{array}$ \\
\cline { 2 - 4 } & $\begin{array}{l}10 \% \text { profit fees; } 5 \% \\
\text { withdrawal fees }\end{array}$ \\
\hline
\end{tabular}

\section{FUNDAMENTAL CONCEPTS AND GENERAL FRAMEWORK}

\subsection{ARBITRAGE AND MARKET MISPRICINGS}

As previously described, the purpose of a prediction market is for traders to aggregate information and reach a common market price that reflects the likelihood of the underlying event's occurrence. The predictive power of a prediction market, then, relies on appropriate pricing of its market contracts. As market pricing is determined by the free exchange of contracts, the forecasting ability depends on the rationality of market participants to aggregate information, observe market prices, and trade accordingly.

For many contracts, the question of whether the contract is priced accurately is a subjective one. The pricing of standalone market contracts such as "Will the American Health Care Act pass?" is a subject of debate by informed traders. For market contracts that are interdependent, however, it is possible to objectively determine that the set of related contracts as a whole is mispriced. Consider the set of prediction market contracts concerning the winner of the 2016 U.S. presidential election; political prediction markets hosted individual contracts representing every officially-announced candidate and many other plausible candidates. As there is only one election winner, the sum of all individual contract prices should 
not exceed the payout amount. The markets hosted by IEM often include a "rest of field" contract that is satisfied if none of the individual-candidate contracts are. In this case, then, the total price should equal the payout amount exactly, with any gains by one candidate's contract coming directly at the expense of all other candidates' contracts. However, in practice, prices may not be so ideally coordinated, and could present opportunities for arbitrage.

For example, in Table 3, hypothetical scenarios of linked markets are evaluated for such arbitrage opportunities. These cases represent examples of successful buy-all-contracts and sell-all-contracts arbitrage, as well as a case in which there is no profitable arbitrage trade possible.

An actual observed example of a mispriced PredictIt market with profitable arbitrage is presented in Table 4. In this case, the nominal mispricing (arbitrage profit before fees) to sell one share of each contract is $\Pi_{n o m}=\sum_{i}^{N} \beta_{i}-p=21 \not$; with PredictIt's profit fee, the arbitrage profit is reduced to 9.1ф. By trading the optimal share distribution shown in the right column of Table 4, a profit of $13.0 \notin$ can be realized. If the bid volume allows the trader to trade up to the $\$ 850$ contract limit (limited by the cheapest contract, Biden) at these prices, then a profit of approximately $\$ 113$ can be earned.

In light of such potential mispricings on PredictIt, an observant trader will note that the contract pricing amounts to a riskless profit, an arbitrage

Table 3. Hypothetical examples of linked markets with payout $p=\$ 1$ that are evaluated for arbitrage opportunities. (Top-left) In this market, one could buy every contract at the ask price and receive the payout, earning $\$ 1-\$ 0.95=\$ 0.05$ per share before fees. (Top-right) In this market, one could sell every contract at the bid price and pay the payout, earning $\$ 1.06-\$ 1=\$ 0.06$ per share before fees. (Bottom) In this market, there is no arbitrage opportunity. Please note $1 \mathrm{c}$ (cent) $=\$ \mathbf{0 . 0 1}$.

\begin{tabular}{|c|c|c|}
\hline Contract & $\operatorname{Bid}(\phi)$ & Ask ( $\phi)$ \\
\hline Candidate 1 & 50 & 52 \\
\hline Candidate 2 & 25 & 26 \\
\hline Candidate 3 & 10 & 11 \\
\hline Candidate 4 & 5 & 6 \\
\hline Sum & 90 & 95 \\
\hline
\end{tabular}

\begin{tabular}{|l|c|c|}
\hline Contract & Bid $(\boldsymbol{\phi})$ & Ask $(\boldsymbol{\phi})$ \\
\hline Candidate 1 & 57 & 58 \\
\hline Candidate 2 & 28 & 29 \\
\hline Candidate 3 & 12 & 13 \\
\hline Candidate 4 & 9 & 10 \\
\hline Sum & $\mathbf{1 0 6}$ & 110 \\
\hline
\end{tabular}

\begin{tabular}{|l|c|c|}
\hline Contract & Bid $(\boldsymbol{\phi})$ & Ask $(\boldsymbol{\phi})$ \\
\hline Candidate 1 & 57 & 58 \\
\hline Candidate 2 & 26 & 27 \\
\hline Candidate 3 & 10 & 11 \\
\hline Candidate 4 & 5 & 6 \\
\hline Sum & 98 & 102 \\
\hline
\end{tabular}


Table 4. PredictIt contract bid/ask prices for linked market for the winner of the 2016 U.S. presidential election. Prices were observed on April 6, 2016 at 5:40pm EDT. The optimal share distribution is presented in the right-most column.

\begin{tabular}{|l|c|c|c|}
\hline Contract & Bid $(\boldsymbol{\phi})$ & Ask $(\boldsymbol{\phi})$ & $\boldsymbol{n}_{\boldsymbol{i}}$ \\
\hline Clinton & 60 & 61 & 1.062 \\
\hline Trump & 19 & 20 & 1.017 \\
\hline Cruz & 14 & 15 & 1.012 \\
\hline Sanders & 13 & 14 & 1.011 \\
\hline Kasich & 6 & 7 & 1.004 \\
\hline Ryan & 4 & 5 & 1.002 \\
\hline Romney & 3 & 4 & 1.001 \\
\hline Biden & 2 & 3 & 1 \\
\hline Sum & 121 & 129 & \\
\hline
\end{tabular}

opportunity. If one can buy contracts representing all possibilities for a total price less than the payout, then an arbitrageur can capture that difference by buying shares in every contract (see example in Table 3, top-left). In practice, this strategy is riskless, unless there remains a possibility that none of the candidates win. If there exists an "all-other" contract as in IEM markets, then risk can be eliminated. Neglecting the chance of an outsider win but accounting for fees, the profit can be calculated as:

$$
\begin{aligned}
\Pi_{\text {buy }- \text { all }}= & \text { payout }- \text { profit fee }- \text { withdrawal fee }- \text { purchase cost } \\
& - \text { transaction fee }- \text { deposit fee } \\
= & n p-n\left(p-\alpha_{w c}\right) f_{p}-\left(n p-n\left(p-\alpha_{w c}\right) f_{p}\right) f_{w}-n \sum_{i}^{N} \alpha_{i}-n N f_{t}-\mathrm{i} f_{d} \\
= & n\left[\left(p-f_{p}\left(p-\alpha_{w c}\right)\right)\left(1-f_{w}\right)-\sum_{i}^{N} \alpha_{i}-N f_{t}\right]-f_{d} \\
& \Pi_{b u y-a l l} \geq n\left[\left(p-f_{p}\left(p-\alpha_{\min }\right)\right)\left(1-f_{w}\right)-\sum_{i}^{N} \alpha_{i}-N f_{t}\right]-f_{d}
\end{aligned}
$$

where $\alpha_{i}$ 's are the ask prices, $\alpha_{w c}$ is the ask price of the winning contract, $n$ is the number of shares purchased per contract, and $N$ is the number of unique contracts available (or number of candidates). Eq. (2.1) represents the profit realized when a certain candidate wins, whereas Eq. (2.2) represents the minimum certain profit, which may increase depending on the winner. The payout amount $p$ and fee amounts $f_{d^{\prime}}, f_{p}, f_{t^{\prime}}, f_{w}$ for several political prediction markets are given in Table 5 . 
Table 5. Prediction Market Payouts, Fees, and Limits for IEM and PredictIt, with Nadex and Predictious given for comparison (University of Iowa, 2016; Victoria University of Wellington, 2015a; Nadex, 2017; Pixode, 2017). Note that the contract limit for IEM includes investment in all contracts (account limit); the Nadex trading fee is \$1 per share for the first 50 shares only and \$1 per share at settlement if in-the-money; the trading fee for Predictious is a function of the contract price, with the highest amount presented. Note "mBTC" refers to 1/1000 of a bitcoin.

\begin{tabular}{|c|l|c|c|c|c|}
\hline & Type & IEM & Predictlt & Nadex & Predictious \\
\hline$p$ & Payout & $\$ 1$ & $\$ 1$ & $\$ 100$ & $10 \mathrm{mBTC}$ \\
\hline$f_{d}$ & Deposit Fee & $\$ 5$ & 0 & 0 & 0 \\
\hline$f_{p}$ & Profit Fee & 0 & $10 \%$ & 0 & 0 \\
\hline$f_{t}$ & Trading Fee & 0 & 0 & $\$ 2$ & $0.1 \mathrm{mBTC}$ \\
\hline$f_{w}$ & Withdrawal Fee & 0 & $5 \%$ & 0 & 0 \\
\hline$c_{L}$ & Contract Limit & $\$ 500$ & $\$ 850$ & $2500+$ & none \\
\hline
\end{tabular}

Per share traded, Eq. (2.2) reduces to the following relations for the aforementioned markets:

$$
\Pi_{b u y-a l l} \geq\left\{\begin{array}{l}
\$ 1-\sum_{i}^{N} \alpha_{i}, I E M \\
\$ 1-f_{p}\left(\$ 1-\alpha_{\min }\right)\left(1-f_{w}\right)-\sum_{i}^{N} \alpha_{i}, \text { PredictIt }
\end{array}\right.
$$

Similarly, if one can sell contracts for a total price greater than the payout, then an arbitrageur can capture that difference as profit (see example in Table 3, top-right). This opportunity is inherently riskless, and in the exceptional case that none of the listed candidates win, the profit is significant.

The sell-all arbitrage profit can be calculated as:

$$
\begin{aligned}
& \Pi_{\text {sell-all }} \begin{array}{c}
\text { revenue }- \text { profit fee }- \text { withdrawal fee }- \text { payout }- \text { transaction fee }- \\
\text { deposit fee }
\end{array} \\
& =n \mathrm{i}\left[\sum_{i}^{N} \beta_{i}-f_{p}\left(\sum_{i}^{N} \beta_{i}-\beta_{w c}\right)-f_{w}\left(\sum_{i}^{N} \beta_{i}-f_{p}\left(\sum_{i}^{N} \beta_{i}-\beta_{w c}\right)\right)-p-N f_{t}\right]-\mathrm{i} f_{d} \\
& =n\left[\left(1-f_{w}\right)\left(\left(1-f_{p}\right) \sum_{i}^{N} \beta_{i}+f_{p} \beta_{w c}\right)-p-N f_{t}\right]-f_{d} \\
& \Pi_{s e l l-a l l} \geq n\left[\left(1-f_{w}\right)\left(\left(1-f_{p}\right) \sum_{i}^{N} \beta_{i}+f_{p} \beta_{\min }\right)-p-N f_{t}\right]-f_{d}
\end{aligned}
$$


where $\beta_{i}$ 's are the bid prices and $\beta_{w c}$ is the bid price of the winning contract. As with the buy-all case, Eq. (2.4) represents the profit realized when a certain candidate wins, whereas Eq. (2.5) represents the minimum certain profit, which may increase depending on the winner. Per share traded, this reduces to the following relations for the aforementioned markets:

$$
\Pi_{\text {sell-all }} \geq\left\{\begin{array}{l}
\sum_{i}^{N} \beta_{i}-\$ 1, \text { IEM } \\
\left(\left(1-f_{p}\right) \sum_{i}^{N} \beta_{i}+f_{p} \beta_{\text {min }}\right)-\$ 1, \text { PredictIt }
\end{array}\right.
$$

For the purpose of this analysis, arbitrageurs are assumed to be pricetakers, buying at the prevailing ask price and selling at the bid price. Likewise, deposit and withdrawal fees have also been neglected in Eq. (2.6) and in subsequent analysis (or assumed to be zero for simplicity) because these fees do not represent marginal costs of engaging in arbitrage. Deposit fees may play a role in the entry decision for new traders wishing to enter the market simply to exploit arbitrage opportunities. However, these fees are negligible for analyzing arbitrage profits for existing traders who have presumably already incurred this cost. Further, every trader pays withdrawal fees when taking their money out of the website, regardless of whether they engaged in any trade at all and regardless of whether it was an arbitrage trade or not.

The IEM and PredictIt frequently host interdependent markets in a linked format. On IEM, traders can purchase individual contracts and sell back a complete bundle to execute a buy-all arbitrage trade, or buy the bundle and sell the constituents to execute a sell-all arbitrage trade. On PredictIt, a risk calculation is performed automatically upon trading, returning traders any money invested greater than the maximum possible loss. These mechanisms effectively allow traders to capture arbitrage profits without waiting until the market settlement, enabling repeated arbitrage trades until the opportunity disappears or the contract limit is reached. As the trader can continue to reuse the initial investment, deposit and withdrawal fees need only be assessed at the end of a series of trades, not on each individual one. Thus, while deposit and withdrawal fees may factor into individuals' decisions to enter into a market (and potentially into their choice regarding which market to enter), these are not considered marginal costs for exploiting arbitrage opportunities. Also note that taxes have not been considered in this analysis as tax rates and policies may depend on the trader's domicile and nationality. In the United States, for example, prediction market winnings may be classified as miscellaneous or gambling income and subject to income taxation (Victoria University of Wellington, 2015a).

In a market without profit fees $\left(f_{p}=0\right)$, selling one share of each contract would result in an outcome-independent payoff, excluding the case in which 
the winning candidate is not represented by a contract. However, if fees are taken as a percentage of profit on each contract, as in PredictIt markets, then the outcome-independent result is generally not realized by trading a uniform number of shares. Instead, the profit from the worst-case profit (2.6) is immediately distributed to the trader, with the possibility of additional profit at market expiration. To the closest integer values, an astute trader can minimize this effect by varying the number of shares traded for each contract $n_{j}$, depending on their bid price $\beta_{j}$ and the profit fee $f_{p}(2.7)$. This can be derived by setting equal the profit from all contracts (e.g. $i$ and $j$ ) in the linked market:

$$
\begin{aligned}
\vec{n} \cdot \vec{\beta}-n_{i} p-\left(\vec{n} \cdot \vec{\beta}-n_{i} \beta_{i}\right) f_{p} & =\vec{n} \cdot \vec{\beta}-n_{j} p-\left(\vec{n} \cdot \vec{\beta}-n_{j} \beta_{j}\right) f_{p} \\
-n_{i} p+n_{i} \beta_{i} f_{p} & =-n_{j} p+n_{j} \beta_{j} f_{p} \\
n_{i}\left(p-\beta_{i} f_{p}\right) & =n_{j}\left(p-\beta_{j} f_{p}\right) \\
n_{j} & =n_{i} \frac{\left(p-\beta_{i} f_{p}\right)}{\left(p-\beta_{j} f_{p}\right)}
\end{aligned}
$$

Where $\vec{n}$ is the vector representing the number of shares traded and $\vec{\beta}$ is the vector representing the bid prices, respectively, of all contracts in the linked market. The profit realized by using this optimal weighting is:

$$
\begin{aligned}
& A=\sum_{i}^{N} \beta_{i}\left(\frac{p-\min (\vec{\beta}) f_{p}}{p-\beta_{i} f_{p}}\right) \\
& \Pi_{o p t} \geq A-p-(A-\min (\vec{\beta})) \cdot f_{p}
\end{aligned}
$$

An instant refund of arbitrage profits allows the trader to leverage a small amount of capital to establish a large arbitrage position up to the contract limits imposed by the market organizer. If the market is sufficiently large that the trader does not influence the price, the profit can then be calculated as $\Pi_{\text {opt }} * n_{\max }$ where $n_{\max }=c_{L} /(p-\min (\vec{\beta}))$ refers to the maximum allowable number of shares to reach the contract limit. IEM arbitrageurs are far less restricted by the contract limit, as the arbitrage trading technique does not require contract retention; in contrast, PredictIt traders retain the contracts until the position is closed or settled.

Without fees $\left(\left\{f_{d^{\prime}}, f_{p^{\prime}} f_{t^{\prime}} f_{w}\right\}=0\right)$, it remains profitable to pursue arbitrage trades as long as the price sum does not equal the payout. With fees included, such trading is profitable only if the arbitrage proceeds exceed the fees. For PredictIt traders employing the sell-all strategy and varying the number of 
shares by Eq. (2.7), the realization of arbitrage profits when $\Pi_{\text {opt }}>0$ is limited only by the trader's ability to approximate the optimal share counts by integers and by the contract limit. For less-sophisticated PredictIt 'sell-all' arbitrageurs that sell equal numbers of all contracts, arbitrage trading only remains profitable when $\sum_{i}^{N} \beta_{i} \geq\left(\frac{p-\min (\vec{\beta}) f_{p}}{1-f_{p}}\right)$. In PredictIt markets, the minimum bid price is often the minimum trading price: $1 \phi$. In this case, the minimum sum of bid prices to allow arbitrage trading is $\$ 1.11$. For bid price sums less than this amount and a minimum bid price of $1 \phi$, profitable arbitrage trading proves difficult, despite the nominal mispricing.

Note that because the PredictIt profit fee in sell-all arbitrage is assessed on each component contract, in the steady state, $\sum_{i}^{N} \beta_{i}$ tends towards $\left(\frac{p-\min (\vec{\beta}) f_{p}}{1-f_{p}}\right)$. However, consider an alternative formulation in which profit fee for sell-all arbitrage is assessed on the entire arbitrage transaction (i.e. set of contracts rather than each individual contract): $n \sum_{i}^{N} \beta_{i}-n p$, instead of $\sum_{i}^{N} \beta_{i}-n \beta_{w c}$. In this case,

$$
\Pi_{\text {sell-all }}^{*}=n\left[\left(1-f_{w}\right)\left(\left(1-f_{p}\right) \sum_{i}^{N} \beta_{i}+f_{p} p\right)-p-N f_{t}\right]-f_{d}
$$

Assuming constant $n$ and $\left\{f_{d^{\prime}}, f_{t^{\prime}} f_{w}\right\}=0$,

$$
\begin{aligned}
& \Pi_{\text {sell-all }}^{*}=n\left(1-f_{p}\right) \sum_{i}^{N} \beta_{i}+n f_{p} p-n p \\
& \Pi_{\text {sell-all }}^{*}=n\left(1-f_{p}\right)\left(\sum_{i}^{N} \beta_{i}-p\right)
\end{aligned}
$$

Thus, as can be seen from Eq. (2.10), $\sum_{i}^{N} \beta_{i}$ tends towards $p$ in the steady state, eliminating mispricing. This is one solution that Predictlt could implement in order to prevent chronic mispricing resulting from sell-all arbitrage.

\section{ANALYSIS AND RESULTS}

\subsection{MISPRICINGS IN PREDICTIT VS. IEM - U.S. 2016 ELECTION}

In this section, we probe the existence of mispricings in the PredictIt and IEM markets for the 2016 U.S. elections, and discuss key factors of mispricings, such as profit fees and contract limits. Specifically, we use market data from the general presidential election in PredictIt and the Democratic and Republican 
nomination primary elections from both PredictIt and IEM. Both markets provide daily trade data including opening trade price, closing trade price, high trade price, low trade price, and trade volume. ${ }^{2}$ Arbitrage opportunities and market mispricings are evaluated using the sell-all arbitrage from the framework above (2.6) without consideration of withdrawal fees and using the close price as the primary estimate of the bid price. The optimal share trading strategy (2.8) was not used, given the lack of knowledge of the leading bid contract sizes at every point in time.

We find that significant arbitrage opportunities existed in the 2016 presidential election markets hosted by PredictIt. The prices of individual contracts and the sum of the prices are presented for PredictIt's general election, Democratic nomination, and Republican nomination markets in Figure 1 (left), with the sell-all arbitrage profit plotted in Figure 1 (right). For nearly the entire duration of the markets, the sum of the prices significantly exceeded the payout value of $\$ 1$, indicating that the markets were consistently mispriced.

A significant change appears in the market behavior around October 2015. At this time, the price sum falls precipitously in all three markets, consequently reducing arbitrage profits. After this point, arbitrage profits continue to exist in the general election and Republican nomination markets at a lesser profit value, and arbitrage profit in the Democratic nomination market ceases. This steep drop corresponds to PredictIt's introduction of linked markets (Victoria University of Wellington, 2015b), which is discussed in Sec. 4.2.

In contrast to the findings from PredictIt, we find that the IEM Democratic and Republican nomination markets did not experience the same persistent mispricings that were endemic to equivalent markets in PredictIt. Consider the Republican primary markets from PredictIt and IEM depicted in Figure 1 (bottom-left) and Figure 2 (right), respectively. The comparable IEM contract set shows some evidence of mispricing as the sum of the contract prices is often above or below the payout amount. ${ }^{3}$ However, such IEM mispricings were short-lived, with the total price not deviating from the payout amount for more than a several days at a time. In contrast, the difference between the PredictIt price sum and the payout was much greater in magnitude and persisted through nearly the entire primary election season. Similar behavior can be

\footnotetext{
2 We use closing trade prices rather than bid/ask prices, as bid/ask prices were not available: $\operatorname{bid}=\max (0, \min ($ close, high - increment $))$ where the price increment is $1 \phi$ for PredictIt and $0.1 \notin$ for IEM. This estimate is conservative (predicts less mispricing $\&$ arbitrage profit) than leading bid estimates from literature (Corwin and Schultz, 2012; Abdi and Ranaldo, 2017). See Appendix for more details on these estimation methods.

3 Further, the "mispricing" we observe in the IEM may be considered virtually nonexistent if bid/ask price data were available. However, we do not expect the use of trade prices, rather than bid/ask prices, to explain away large and persistent mispricings observed in PredictIt.
} 

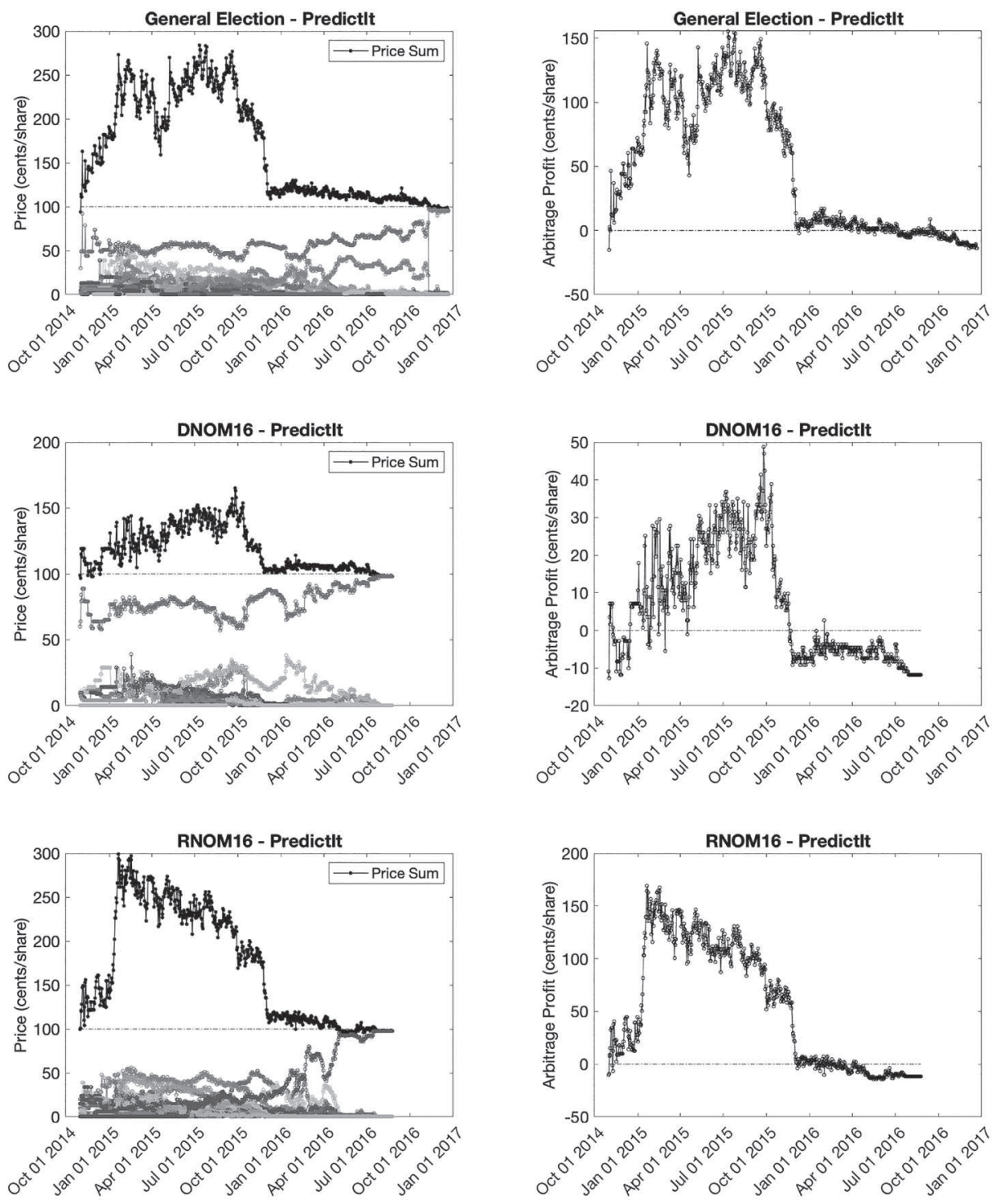

Figure 1. Prices of U.S. presidential market contracts in three PredictIt markets are given at left: (top) general election, (middle) Democratic nomination, (bottom) Republican nomination. The contract prices of each candidate are presented in greyscale, while the total price is shown in black. At right, the arbitrage profit is given, calculated by Eq. (2.6).

observed for the Democratic primary and general election markets as well (see Figure 1 (middle-left) and Figure 2 (left)). Relative to the PredictIt markets, the IEM markets' price sum deviated little from the payout value of $\$ 1$ and seldom held greater or less than $\$ 1$ for more than a few days at a time. Consequently, profitable arbitrage trading in the IEM markets was limited and short-lived. 

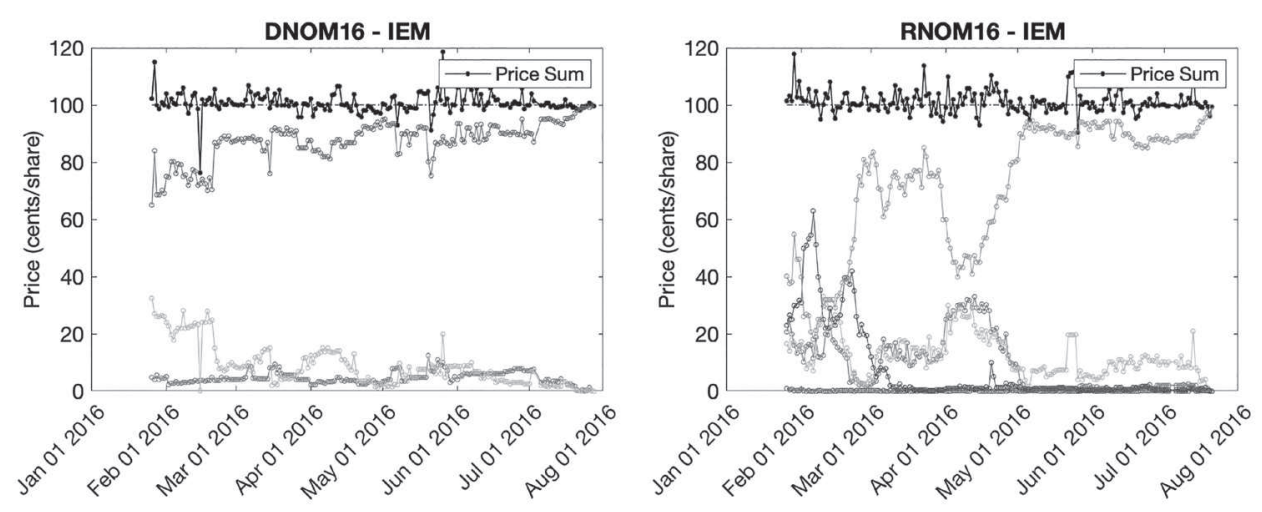

Figure 2. Prices of U.S. presidential market contracts in two IEM markets are given: (left) Democratic nomination, (right) Republican nomination. The contract prices of each candidate are presented in greyscale, while the total price is shown in black.

\subsubsection{PROFIT FEES}

To highlight the impact of profit fees on arbitrage, we present the arbitrage profits for the two PredictIt markets from 2016 at the real value of $f_{p}=10 \%$ against a hypothetical no-fee market $\left(f_{p}=0\right)$ in Figure 3 . At the real $f_{p}$ profit fee rate, the arbitrage profit was approximately zero after December 2015, creating no profit incentive for traders to erode the market mispricing. Illustrating the effect of PredictIt's 10\% profit fee, the markets remained at the mispriced equilibrium, distinct from the efficient no-fee market equilibrium wherein the price sum equals the payout.

The observations given above provide insight into the market design of American political prediction markets and their ability to effectively forecast election outcomes. Market data indicates that PredictIt markets for the 2016 presidential elections were consistently mispriced over the life of the markets, with the price sum exceeding the payout value. This was, in part, due to the high investment and distant payout required to realize arbitrage profits, but the mispricing remained even after PredictIt introduced linked-contract pricing in October 2015, as can be seen in Figure 3 (and will be discussed further in the next section). Analysis of arbitrage profitability suggests that PredictIt's $10 \%$ profit fee significantly impacts the profit incentive to trade upon and reduce market mispricings, allowing the market to remain at a mispriced equilibrium (Figure 3). In contrast, such mispricings did not exist in IEM. Comparing the two markets, this difference is likely due to the IEM's fee structure, which charges no fee on profits. Consequently, IEM traders can profitably trade the price sum down to the level of the payout, within the limits of bid/ask spreads. 

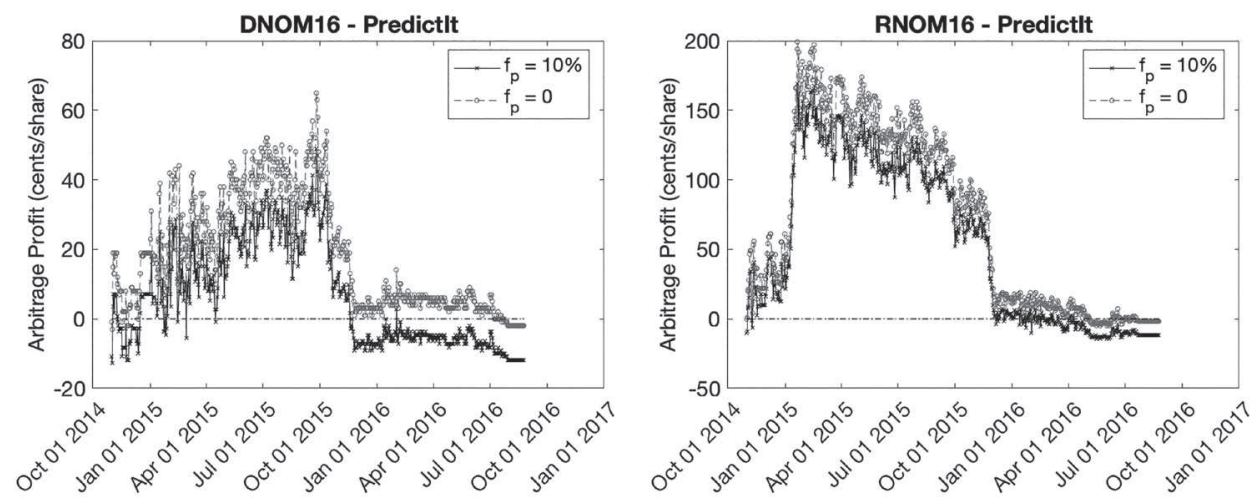

Figure 3. Arbitrage profits in two PredictIt markets are given, calculated by Eq. (2.6) with the existing profit fee, $f_{p}=10 \%$ and no profit fee, $f_{p}=0$ : (left) Democratic nomination, (right) Republican nomination.

\subsubsection{CONTRACT LIMITS}

An additional difference between PredictIt and IEM that might compound with the effects of the profit fees described above are contract limits. As aforementioned, arbitrage-seeking traders on IEM are less impacted by the $\$ 500$ contract limit than PredictIt traders are. Completing a buy-all or sell-all arbitrage trade involves buying/selling individual contracts and selling/buying a complete bundle. Once the pair of trades is completed, no contracts need be retained, resetting the contract value total to zero. In contrast, PredictIt traders retain the contracts until the position is closed or settled, making the $\$ 850$ limit a hard constraint.

Combined with the profit fees, the consequence of this implementation difference is that IEM traders can continually execute arbitrage trades whenever mispricings exist, whereas PredictIt traders can only profitably do so when (1) the mispricing is sufficiently large to overcome the profit fee and (2) they have not yet reached the contract limit. These combined limitations on PredictIt traders' ability to erode down mispricings through arbitrage trade likely contributes to lasting existence of the mispricings.

\subsubsection{TRADER INEXPERIENCE AND LIMITS ON THE NUMBER OF TRADERS}

Other contributing factors to PredictIt's enduring market mispricings may be trader experience and the limited number of traders per market. In contrast to IEM, PredictIt appeals to a broader audience by advertising online, has numerous markets, and can be instantly funded by credit card (rather than requiring a check or wire transfer). Thus, its trading population may be less experienced at identifying and executing arbitrage trades, consistent with 
findings by Tetlock (2004) and Oliven and Rietz (2004). Further, in the context of the limited number of traders per market $(5,000$ for PredictIt per CFTC), inexperienced traders may crowd out experienced, arbitrage-aware traders. Trader inexperience may also compound with contract limits imposed by the CFTC, as the experienced traders who identify arbitrage trades can only trade a limited volume to decrease them. Nonetheless, consequences of trader experience may ease with time, as traders gain knowledge and experience. Some traders have taken to educating others on arbitrage identification; this topic has become a recurring discussion on PredictIt's online forums, has been published in books (Chougule, 2016), and has been developed as an opensource browser plug-in (Raznikov, 2017).

\subsection{MARGIN-LINKING, LIQUIDITY, AND MARKET DESCRIPTIVENESS}

In this section, we discuss the impact of margin-linking, high trading volume, and market descriptiveness (the number of unique contracts with non-zero price) on arbitrage profits. These factors were chosen based on their relevance, data availability, and their goodness of fit. ${ }^{4}$ We first describe these variables and then test their influence on arbitrage using an ordinal least squares (OLS) regression on PredictIt's 2016 election data. ${ }^{5}$

\subsubsection{MARGIN-LINKING}

In October 2015, PredictIt introduced "margin linking" or linked-contract pricing. Prior to linked contract-pricing, PredictIt's trading system deducted funds from a trader's account if a trader incurred a loss on a given contract, without taking into consideration multiple contracts purchased by the same trader that would reduce the total loss incurred by the trader (Schmitz and Rothschild, 2019). With linked-contract pricing, PredictIt started to take into account linked outcomes of multiple contracts purchased by any individual trader, and deducted only the maximum possible loss amount across all linked

\footnotetext{
${ }^{4}$ For example, the measure of market descriptiveness was considered between (1) number of unique contracts, (2) number of unique contracts with non-zero price, and (3) number of unique contracts with non-zero price and non-zero daily volume. Each of these alone was found to have a statistically significant relationship with the arbitrage profit, but option (2) was the most significant factor by T-statistic, adjusted $\mathrm{R}^{2}$, and F-statistic. When included as the measure of market descriptiveness in the full OLS analysis (Eq. 3.1), Option (2) maximized the adjusted $\mathrm{R}^{2}$ and F-statistic.

5 Specifically, we consider data from the following 2016 election markets: presidential general election (USPRES), winning political party (PARTY), Democratic primary nomination (DNOM), Republican primary nomination (RNOM), Democratic vicepresident candidate (DVP), Republican vice-president candidate (RVP), Secretary of State (SECSTATE) on 1/31/2018, Secretary of Defense (SECDEF) on 2/28/2017.
} 
contracts. Such linked contract-pricing permits traders to leverage larger positions with less money invested, which in turn allows them to pursue arbitrage trading more aggressively. Restated, the instant payouts when arbitrage is realized allows traders to continue to trade from a small investment, whereas the prior scheme rewarded arbitrageurs only after the market ended, posing a far lesser return on investment.

We examine the impact of the October 2015 policy change that created linked-contract pricing on PredictIt. Firstly, it is observed that the PredictIt market mispricing persisted even after the October 2015 policy change that created linked-contract pricing. The magnitude of the mispricing fell significantly in the markets observed (Figure 1), but the price sum remained above the payout value for the remainder of the market term. Despite the continuing mispricing mentioned in Sec. 4.1., examination of the arbitrage profitability for the Democratic and Republican nomination markets reveals that arbitrage trades were generally not profitable after December 2015. The effect of margin linking observed here is similar to that observed by Schmitz and Rothschild (2019) using sum of mid-quote prices (average of the bid and ask prices) from the state of Iowa's presidential primaries in 2016.

\subsubsection{LIQUIDITY}

Market illiquidity is considered to be a transaction cost for arbitrageurs whose trades contribute to achieving price efficiency. Alternatively, liquidity can also represent non-informational or noise trading, which could negatively impact prediction markets. Empirical evidence on the subject is mixed, supporting both negative and positive relationships between increased liquidity and price efficiencies (Tetlock, 2008). We thus examine the impact of greater liquidity, measured by trading volume, on arbitrage profits in PredictIt.

We observe that high trading volume did not preclude mispriced markets in PredictIt. In fact, markets exhibited the most severe pricing inconsistencies when trading volume was the highest. Correlation between high trading volume and market mispricing was especially apparent in PredictIt's Secretary of Defense and Secretary of State markets, shown in Figure 4. In these markets, the total price exceeded the payout value specifically when the daily trading volume was highest.

\subsubsection{MARKET DESCRIPTIVENESS}

Another aspect of market design that differs between IEM and PredictIt is market descriptiveness, measured by the number of uniquely traded contracts with non-zero price. For example, PredictIt hosted markets for ten candidates for the Democratic nomination and 21 candidates for the Republican nomination which exhibited significant mispricing; in contrast, IEM hosted markets for two and four candidates, respectively, each with an additional rest-of-field 

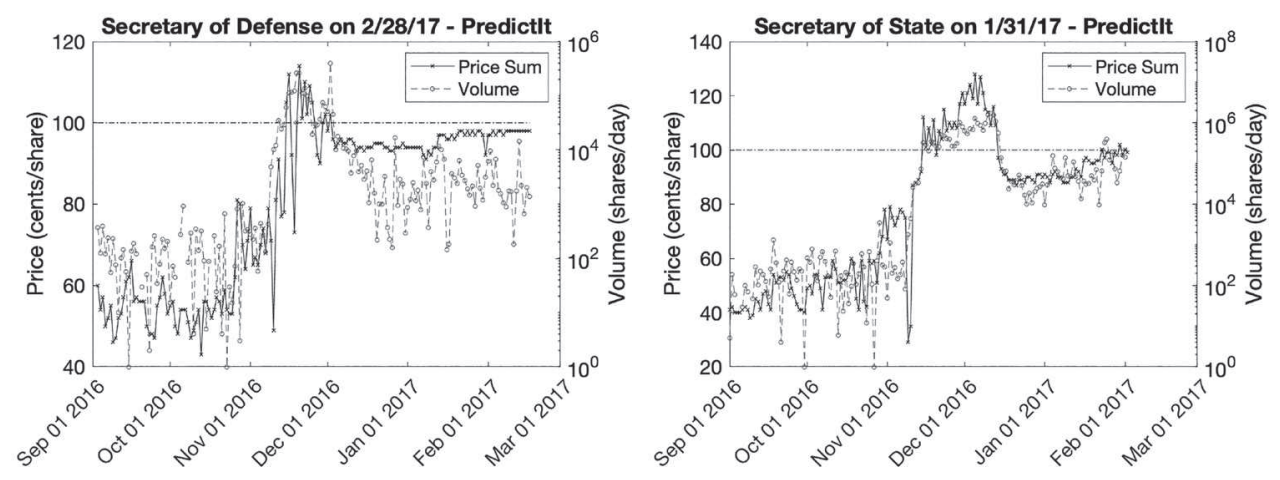

Figure 4. Total price and daily trading volume in the PredictIt markets for the U.S. Secretaries of Defense (left) and State (right).

market and exhibited very little mispricing. There may exist a tradeoff between market descriptiveness - i.e. valuing a broad field of candidates - and efficient market pricing. We examine the impact of the number of uniquely traded contracts on arbitrage profits below.

\subsubsection{ASSOCIATION WITH ARBITRAGE}

In order to more precisely discern the relationship between margin-linked markets, trading volume, and the number of non-zero-priced contracts on arbitrage profits, we conduct an OLS (3.1) on the market data to predict sell-all arbitrage profit $\left(\hat{\Pi}=\Pi_{\text {true }}\right)$ from the following PredictIt markets: 2016 general election winner, Democratic presidential nomination, Democratic vicepresidential nomination, Republican presidential nomination, Republican vicepresidential nomination, winning presidential party, Secretary of Defense on 2/26/2017, and Secretary of State on 1/31/2017.

$$
\widehat{\Pi}=c_{0}+c_{1} \log _{10} V+c_{2} N_{a c}+c_{3} L
$$

Explanatory variables are the base-10 logarithm of daily trading volume $\left(\log _{10} V\right)$, the number of candidates represented with non-zero-priced contracts $\left(N_{a c}\right)$, and a binary variable $L$ representing whether the date is before $(L=0)$ or after $(L=1)$ October 1,2015 , the date that PredictIt transitioned to linkedcontract pricing. The results of the ordinary least squares regression are presented in Table 6.

First note that coefficient $c_{3}$ indicates that the arbitrage profit fell significantly, by $54.7 \varnothing$ per share, after the transition to linked markets in October 2015.

Next, the regression also shows that market volume and the number of traded contracts in the market are positively related with arbitrage profit. Each additional candidate market added to the PredictIt market increased the price 
Table 6. Ordinary least squares analysis of arbitrage profit in selected PredictIt markets

\begin{tabular}{|l|c|c|c|c|}
\hline Variable & $\boldsymbol{c}_{0}$ (cents) & $\boldsymbol{c}_{\mathbf{1}}$ (cents) & $\boldsymbol{c}_{\mathbf{2}}$ (cents) & $\boldsymbol{c}_{3}$ (cents) \\
\hline Coefficient & -2.759 & $2.354^{*}$ & $3.672^{*}$ & $-54.712^{*}$ \\
\hline (Std. Error) & $(1.521)$ & $(0.204)$ & $(0.065)$ & $(1.197)$ \\
\hline T-statistic & -1.814 & 11.551 & 56.142 & -45.713 \\
\hline
\end{tabular}

No. of observations $=3592$

Adjusted $\boldsymbol{R}^{2}=0.692$

F-statistic vs. constant model $=2690$

*Statistically significant at $p=0.05$ level

sum by an average of $3.672 \phi$ for the markets observed. This effect may be in part due to the minimum contract price and price increment of $1 \varnothing$ on PredictIt and $0.1 \varnothing$ on IEM; at low prices, the representation error between the true probability and allowable prices may be significant when summed over all candidates. Alternatively, every additional candidate contract in the market increases the effort required to execute arbitrage trades, possibly dissuading potential arbitrageurs. ${ }^{6}$

Finally, a key finding regarding PredictIt's prediction market performance is that higher trading volume did not correlate with betterpriced markets, but in fact the opposite. This runs contrary to previous analyses that have shown that increased liquidity serves to reduce arbitrage profits in commercial futures and options markets (Roll et al., 2007; Deville and Riva, 2007). This finding is generally counter-intuitive as more popular markets are expected to better aggregate information since they allow arbitrageurs to rapidly trade on observed mispricings. Nevertheless, there are a few possible explanations for this result which deserve further analysis in future work. Increased liquidity in the form of increased trading volume could be representing non-informational or noise trading (Tetlock, 2008). There are studies that suggest increased number of inexperienced traders can increase price inefficiency in prediction markets (Tetlock, 2004; Brown et al., 2019; Schmitz and Rothschild, 2019). Another plausible explanation is contract limits. Such limits are imposed per trader on academic American prediction markets by the CFTC as they restrict the ability of traders to enact arbitrage trades to erode the mispricing. These limits pose the sole barrier that prevents a trader from continuously exploiting profitable

\footnotetext{
${ }^{6}$ Note that the tradeoff between market descriptiveness and efficient market pricing is particularly relevant in the absence of automated trading in the PredictIt market. If PredictIt allowed for automated trading like IEM does, trading bots could remove arbitrage opportunities instantaneously, regardless of the number of contracts.
} 
arbitrage opportunities. Contract limits, however, are not without value; limiting the influence of each trader reduces the need for market enforcement against manipulation and insider trading. If the market were sufficiently large to necessitate market enforcement, operation costs and fees might increase. Nevertheless, given that contract limits are imposed, improved market implementation may abate their negative consequences. The specific technique used to execute arbitrage trades on IEM markets is far less limited by contract limits than on PredictIt. This reveals that different market configurations can diminish the effect of contract limits on arbitrage trading.

\subsection{MISPRICINGS IN PREDICTIT FOR THE U.S. 2020 ELECTION}

Finally, we analyze the most recent data available on the Democratic nomination, Republican nomination, and presidential election markets for the 2020 American presidential election from 10/5/2018 to 1/10/2020. As before, arbitrage opportunities and market mispricings are evaluated using the sell-all arbitrage from the framework above (2.6) without consideration of withdrawal fees and using the close price as the primary estimate of the bid price; the optimal share trading strategy (2.8) was not considered.

We find that popular markets on Predictlt have continued to be chronically mispriced in other election cycles. The Democratic nomination, Republican nomination, and presidential election markets for the 2020 American presidential election have consistently evinced bid price totals greater than the payout amount. An illustration is shown in Figure 5, which depicts the daily
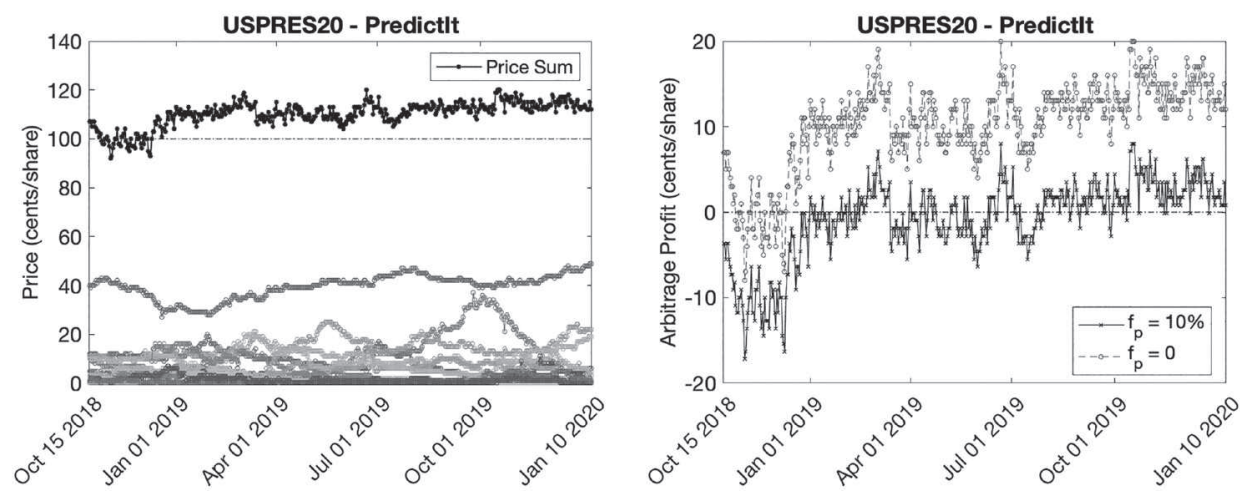

Figure 5. Prices of U.S. presidential market contracts in the 2020 PredictIt general election market is given at left. The contract prices of each candidate are presented in greyscale, while the total price is shown in black. At right, the arbitrage profit is given, calculated by Eq. (2.6). 
price history and arbitrage profit in PredictIt's 2020 American presidential election market; the bid price sum is consistently greater than the payout amount, and profitable arbitrage opportunities appear to exist only in small magnitudes.

\subsection{DURATION AND MAGNITUDE OF MISPRICINGS AND ARBITRAGE - U.S. 2016 AND 2020 ELECTIONS}

Finally, we attempt to place in context the duration and magnitude of mispricings and arbitrage observed on PredictIt. Luckner and Weinhardt (2008), after ignoring extremely small arbitrage opportunities of presumably little interest to traders, reported 229 instances of arbitrage opportunities at $1 \%$ of the portfolio value, which on average lasted 47 minutes and 7 instances arbitrage opportunities at $10 \%$ of the portfolio value, which on average lasted 11 minutes. Similarly, Rhode and Strumpf (2004), observed that large mispricings were short-lived, i.e. 8 to 10 days. In our analysis, arbitrage opportunities at $1 \%$ of value are uncountable as they are incredibly numerous and because they are too short-lived or dynamic. Arbitrage opportunities at $10 \%$ of value or larger are indeed observed, especially prior to PredictIt's introduction of margin-linking. Compared to prior findings, the mispricings and arbitrage profits we observe on PredictIt are large and persistent. For all the markets observed, Table 7 presents the duration of mispricings and of arbitrage profits for three levels: $>5 \phi,>10 \phi$, and $>20 \phi$. On PredictIt's 2016 election markets, mispricings greater than $20 \notin$ lasted a total of 271 days in DNOM, 391 days in RNOM, and 433 days in USPRES, whereas mispricings in equivalent IEM's markets lasted zero days. The trend for arbitrage profits is similar to the trend for mispricings. The case of largest arbitrage profit, $170 \phi$ per share (where cost per share $=100 \phi$ ), is observed in February 2016 in PredictIt's RNOM market. Although the market depth of each position, i.e. number of shares on offer for each candidate/market, cannot be observed in the data, if we assume there are the maximum possible number of shares on offer (i.e. 850) for each candidate/market, the case of largest arbitrage profit amounts to $\$ 1445$. Since that time, arbitrage profit observed is substantially lower. For the 2020 election, the largest arbitrage profit amounts to $\$ 85$. Considering that the trade takes less than an hour to execute, the incentive to engage in arbitrage is not negligible. It is evident from Table 7 that mispricings and arbitrage profits on PredictIt 2016 persisted for much longer than IEM 2016. Further, comparing PredictIt 2020 to PredictIt 2016, mispricings remain endemic, but arbitrage profits have become much more short-lived. 


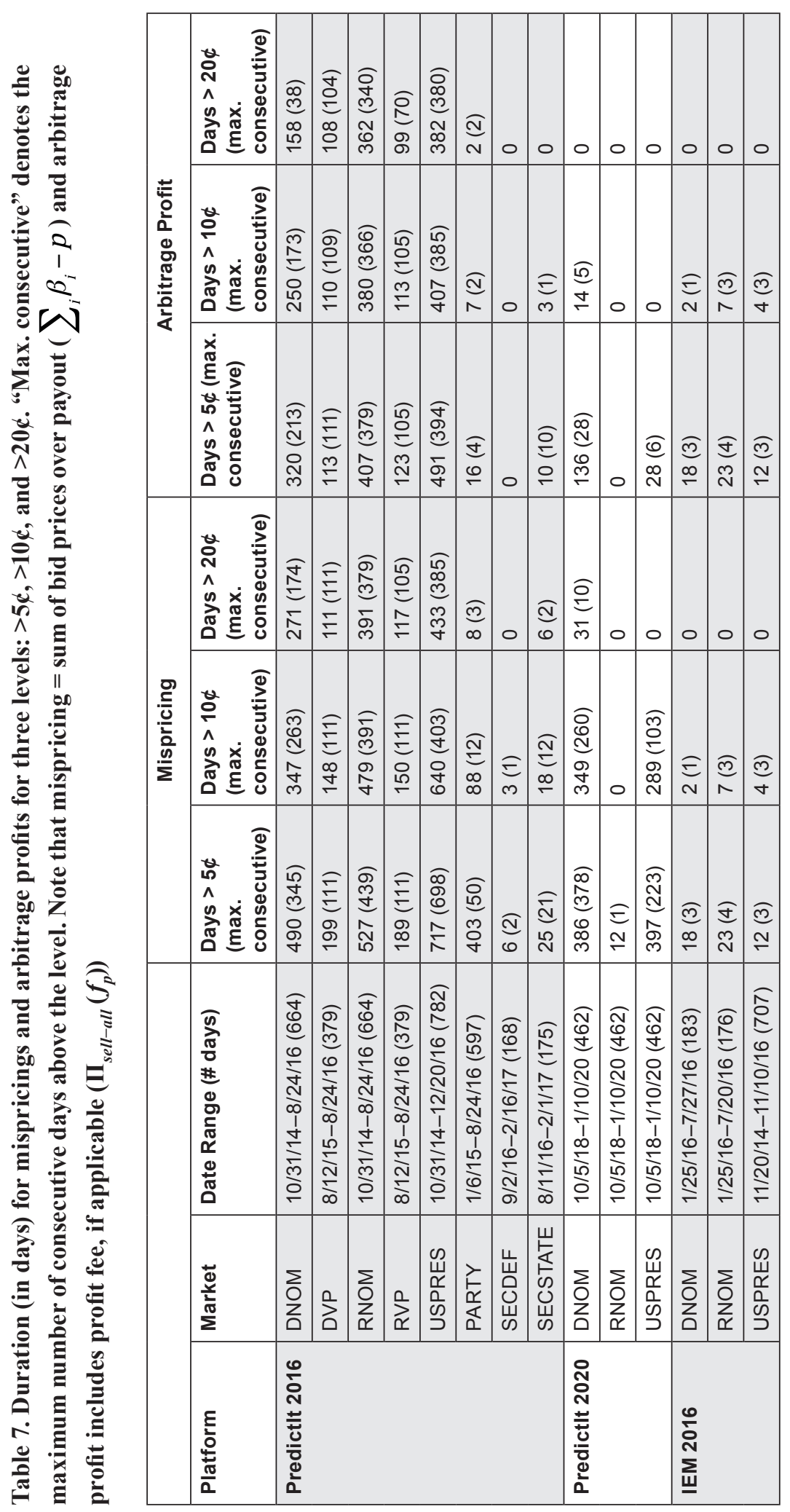




\section{CONCLUSIONS}

Prediction markets are a promising mechanism for reducing election uncertainty. They are powerful tools for aggregating information and forecasting a wide variety of events, often outperforming polling data. These markets are effective predictors so long as their pricing remains efficient.

In this paper, we highlight the need for updated research on price efficiency in political prediction markets, and in particular, on the weakest condition for efficiency, intra-market arbitrage. We provide a systematic comparison of the market designs of the two leading political prediction markets, the IEM and PredictIt. We hypothesized that market design features that set PredictIt apart from the IEM pose threats to its efficiency. Consistent with this hypothesis, we demonstrate that the most popular political prediction market that covered the 2016 American presidential elections, PredictIt, exhibited persistent and significant pricing inconsistencies among candidate contracts, which likely detract from its predictive value. We also show that these mispricings persisted despite PredictIt's introduction of linked-contract pricing in October 2015, which was expected to enhance traders' positions and lead to more aggressive arbitrage and reduced mispricings. Further, we present evidence that market pricing inconsistencies of this type have recurred in PredictIt's 2020 presidential election markets. We contrast PredictIt's Democratic and Republican nomination markets with equivalent markets of the IEM, and show that the IEM did not experience such mispricings.

Additionally, despite the expectation of fewer mispricings or arbitrage opportunities due to increased trade volume, we show the opposite to be true. Trade volume was positively correlated with arbitrage profits, further evidencing the unmitigated mispricings of PredictIt. We argue that the design structure of these markets is important in explaining the different outcomes. Profit fees, present in PredictIt and not in the IEM, reduce or eliminate the profit incentive for arbitrageurs to trade down market mispricings. The inclusion of an excessive number of unlikely candidates combined with a relatively coarse price increment may serve to unrealistically increase the price sum.

Additional research is needed for drawing causal links between key market design features, the regulatory framework of election markets, and the efficiency of PredictIt. Further examination of the CFTC-imposed limits and PredictIt's recruitment strategies impacting the composition of traders, potential crowding out of experienced traders, along with the effects of trader composition on mispricing would be beneficial. Moreover, as there is insufficient prior evidence on large and persistent arbitrage, the performance of prediction markets under larger and more persistent arbitrage opportunities remains untested empirically. Our analysis cautions against taking the efficiency and predictive value of political prediction markets for granted by demonstrating the unprecedented extent of mispricings on PredictIt and highlighting aspects of market design likely to be contributors. The lessons learned from this analysis hold broadly for 
other prediction markets and their market designs. Updated research on various aspects of efficiency of existing political markets are needed for ensuring market efficiency and predictive accuracy of existing and emerging prediction market platforms. Prediction market mechanisms may become increasingly important in the near future than previously anticipated owing to their potential for increasing or decreasing political misinformation, and thus there is a need to fine-tune our understanding of these market mechanisms.

\section{REFERENCES}

Abdi, F., \& Ranaldo, A. (2017). A simple estimation of bid-ask spreads from daily close, high, and low prices. The Review of Financial Studies, 30(12), 4437-4480.

Arrow, K.J., Forsythe, R., Gorham, M., Hahn, R., Hanson, R., Ledyard, J.O., Levmore, S., Litan, R., Milgrom, P., Nelson, F.D., Neumann, G.R., Ottaviani, M., Schelling, T.C., Shiller, R.J., Smith, V.L., Snowberg, E., Sunstein, C.R., Tetlock, P.C., Tetlock, P.E., Varian, H.R., Wolfers, J., and, Zitzewitz, E., 2008. The promise of prediction markets.

Auld, T., \& Linton, O. (2019). The behaviour of betting and currency markets on the night of the EU referendum. International Journal of Forecasting, 35(1), 371-389.

Berg, J. E., \& Rietz, T. A. (2019). Longshots, overconfidence and efficiency on the Iowa Electronic Market. International Journal of Forecasting.

Berg, J. E., Forsythe, R., Nelson, F., \& Rietz, T. (2008). Results from a dozen years of election futures markets research. Handbook of Experimental Economic Results, 1, 742-751.

Berg, J. E., Nelson, F. D., \& Rietz, T. A. (2008). Prediction market accuracy in the long run. International Journal of Forecasting, 24, 285-300.

Betfair. (2005). Betfair Online Betting.

Blau, B. M., Griffith, T. G., \& Whitby, R. J. (2019). Information in stock prices: the case of the 2016 US presidential election. Applied Economics, 51(40), 4385-4396.

Brito, J., Shadab, H., \& Castillo, A. (2014). Bitcoin financial regulation: Securities, derivatives, prediction markets, and gambling. Colum. Sci. \& Tech. L. Rev., 16, 144-221.

Brown, A., Reade, J. J., \& Vaughan Williams, L. (2019). When are prediction market prices most informative?. International Journal of Forecasting, 35(1), 420-428

Chen, M. K., Ingersoll Jr, J. E., \& Kaplan, E. H. (2008). Modeling a presidential prediction market. Management Science, 54, 1381-1394.

Chougule, P. (2016, 8). How to Make Money from Political Predictions: A Guide to Generating High Returns from PredictIt Investments. Amazon.

Croxson, K., \& James Reade, J. (2013). Information and efficiency: Goal arrival in soccer betting. The Economic Journal, 124(575), 62-91. 
Corwin, S. A., \& Schultz, P. (2012). A simple way to estimate bid-ask spreads from daily high and low prices. The Journal of Finance, 67(2), 719-760.

Deville, L., \& Riva, F. (2007). Liquidity and arbitrage in options markets: A survival analysis approach. Review of Finance, 11, 497-525.

Ederington, L. H. (1979). The hedging performance of the new futures markets. The Journal of Finance, 34, 157-170.

Forsythe, R., Nelson, F., Neumann, G. R., \& Wright, J. (1992). Anatomy of an experimental political stock market. The American Economic Review, $1142-1161$.

Forsythe, R., Rietz, T. A., \& Ross, T. W. (1999). Wishes, expectations and actions: a survey on price formation in election stock markets. Journal of Economic Behavior \& Organization, 39, 83-110.

Graefe, A. (2017). Political markets. The Sage Handbook of Electoral Behavior. Los Angeles: Sage. FC.

Hayek, F. A. (1945). The use of knowledge in society. The American Economic Review, 519-530.

Julio, B., \& Yook, Y. (2012). Political uncertainty and corporate investment cycles. The Journal of Finance, 67(1), 45-83.

Lewandowsky, S., Ecker, U. K., \& Cook, J. (2017). Beyond misinformation: Understanding and coping with the "post-truth" era. Journal of Applied Research in Memory and Cognition, 6(4), 353-369.

Luckner, S., \& Weinhardt, C. (2008, July). Arbitrage opportunities and marketmaking traders in prediction markets. In 2008 10th IEEE Conference on E-Commerce Technology and the Fifth IEEE Conference on Enterprise Computing, E-Commerce and E-Services (pp. 53-59). IEEE.

Kelly, B., Pastor, L., \& Veronesi, P. (2016). The Price of Political Uncertainty: Theory and Evidence from the Option Market. The Journal of Finance.

Kildal, P., McPherson, T. A., Loftaas, L. R., Valvik, K., \& Bergfjord, O. J. (2012). Arbitrage Trade in Prediction Markets. Journal of Prediction Markets, 6(3)

Majumder, S. R., Diermeier, D., Rietz, T. A., \& Amaral, L. A. (2009). Price dynamics in political prediction markets. Proceedings of the National Academy of Sciences, 106, 679-684.

Manski, C. F. (2006). Interpreting the predictions of prediction markets. Economics Letters, 91, 425-429.

Nadex. (2017). Binary Options | Online Trading platform on Forex, Indices, Commodities | Nadex.

Oliven, K., \& Rietz, T. A. (2004). Suckers are born but markets are made: Individual rationality, arbitrage, and market efficiency on an electronic futures market. Management Science, 50, 336-351.

Page, L. (2012). 'It ain't over till it's over.' Yogi Berra bias on prediction markets. Applied Economics, 44:1, 81-92.

Pixode. (2017, 5 28). Predictious. 
Ray, R. (2006). Prediction Markets and the Financial "Wisdom of Crowds". Journal of Behavioral Finance, 7, 2-4.

Raznikov, P. (2017, 2 3). pi - Automatic Negative Risk Assessment.

Restocchi, V., McGroarty, F., \& Gerding, E. (2019). The temporal evolution of mispricing in prediction markets. Finance Research Letters, 29, 303-307.

Rhode, P. W., \& Strumpf, K. S. (2004). Historical presidential betting markets. Journal of Economic Perspectives, 18(2), 127-141.

Ritterman, J., Osborne, M., \& Klein, E. (2009, November). Using prediction markets and Twitter to predict a swine flu pandemic. In 1st international workshop on mining social media (Vol. 9, pp. 9-17). ac. uk/miles/papers/ swine09. pdf (accessed 26 August 2015)

Roll, R. (1984) A simple implicit measure of the effective bid-ask spread in an efficient market. Journal of Finance, 39. 1127-1139.

Roll, R., Schwartz, E., \& Subrahmanyam, A. (2007). Liquidity and the law of one price: the case of the futures-cash basis. Journal of Finance, 62, 2201-2234.

Rothschild, D., \& Pennock, D. M. (2014). The extent of price misalignment in prediction markets. Algorithmic Finance, 3(1-2), 3-20.

Schoen, H., Gayo-Avello, D., Takis Metaxas, P., Mustafaraj, E., Strohmaier, M., \& Gloor, P. (2013). The power of prediction with social media. Internet Research, 23(5), 528-543.

Schmitz, J., \& Rothschild, D. (2019) Understanding Market Functionality and Trading Success. Working paper. http://researchdmr.com/PredictIt2016.pdf

Servan-Schreiber, E., Wolfers, J., Pennock, D. M., \& Galebach, B. (2004). Prediction markets: Does money matter? Electronic Markets, 14, 243-251.

Sethi, R. (2015). Prediction Market Design.

Sethi, R. (2015). The Price Impact of Margin-Linked Shorts.

Sethi, R. (2016). Fee-Structure Distortions in Prediction Markets.

Spann, M., \& Skiera, B. (2003). Internet-based virtual stock markets for business forecasting. Management Science, 49(10), 1310-1326.

Tetlock, P. (2004). How efficient are information markets? Evidence from an online exchange. Social Science Research Network.

Tetlock, P. C. (2008). Liquidity and prediction market efficiency. Available at SSRN 929916.

Tziralis, G., \& Tatsiopoulos, I. (2012). Prediction markets: An extended literature review. The journal of prediction markets, 1, 75-91.

University of Iowa. (2016, 3 31). IEM - Iowa Electronic Markets. https:/tippie. uiowa.edu/iem/, Accessed 2019-03-01.

U. S. Commodity Futures Trading Commission. CFTC Release PR6224-12: CFTC Issues Order Prohibiting North American Derivatives Exchange's Political Even Derivatives Contracts. http://www.cftc.gov/ PressRoom/ PressReleases/pr6224-12, Accessed 2017-10-15, 2012. Action.

U. S. Commodity Futures trading Commission. (2014, 10 29). CFTC Letter No.14-130—No Action. http://www. cftc.gov/idc/groups/public/@lrlettergeneral/ documents/letter/14-130.pdf, Accessed 2017-10-15, 2014. 
Valenzuela, S., Halpern, D., Katz, J. E., \& Miranda, J. P. (2019). The Paradox of Participation Versus Misinformation: Social Media, Political Engagement, and the Spread of Misinformation. Digital Journalism, 1-22.

Vaughan Williams, L., \& Reade, J. J. (2016). Prediction markets, social media and information efficiency. Kyklos, 69(3), 518-556.

Victoria University of Wellington. (2015, 11 2). Linked Contract Pricing PredictIt. https://www.predictit.org/About/LinkedContractPricing, Accessed 2017-10-15.

Victoria University of Wellington. $(2015,113)$. PredictIt. https://www.predictit. org/, Accessed 2019 03-01.

Vlastakis, N., Dotsis, G., \& Markellos, R. N. (2009). How efficient is the European football betting market? Evidence from arbitrage and trading strategies. Journal of Forecasting, 28(5), 426-444.

Wolfers, J., \& Zitzewitz, E. (2004). Prediction markets. Journal of Economic Perspectives, 18, 107126.

Wolfers, J., \& Zitzewitz, E. (2006). Interpreting prediction market prices as probabilities. Tech. rep., National Bureau of Economic Research. 